УДК 159.923

doi: $10.15330 / p s .10 .1 .148-152$

Леонид Левит

Центр психологического здоровья и образования (Минск, Беларусь)

leolev44@tut.by

\title{
КНИГА БЫТИЯ И СОВРЕМЕННАЯ ПСИХОЛОГИЯ: СОВПАДЕНИЯ И РАСХОЖДЕНИЯ
}

В статье рассматриваются совпадения и различия между библейским сюжетом о первородном грехе и результатами, выявленными современной экспериментальной наукой. Так, показано, что подавляющее большинство людей действительно подвержено закономерностям, которые трактуются религией $в$ качестве божественного наказания за вкушение плодов с дерева познания. Речь идёт о повышенной уязвимости к негативу, быстрой адаптации к позитиву, трансформации кратковременного «добра»в долговременное «зло» и восприятии труда в качестве тягостной необходимости. Таким образом, отмечаемая в христианских источниках «большая склонность человека к злу, нежели к добру» имеет определённые научные подтверждения. Создаётся впечатление, что над «массовым» человеком действительно тяготеют негативные закономерности, которые можно истолковывать как следствие «божественного наказания». По контрасту, свободно выбираемая активность одарённого индивида подчинена противоположным закономерностям: получению качественно особых (в том числе, потоковых) позитивных переживаний благодаря напряжению сил, отсутствию адаптации к позитиву с одновременной повышенной устойчивостью к негативной информации и общераспространённым стрессам, развитию внутреннего потенцииала и успешной самореализации. В частности, последнее наиболее ярко выражено в творческой активности учёного, продолжающего «срывать плоды с дерева познания», тем самылм как бы «нарушая» божественные запреты и общечеловеческие закономерности. В эпоху, когда наука не обнаружила следов «внешнего» источника смысла жизни (включая божественный замысел), на современного думающего человека ложится личная ответственность за создание персональной смысловой конструкции.

Ключевые слова: адаптация, добро, зло, позитивные иллюзии, религия, смысл.

Введение. Как известно, Книга Бытия является первой частью Ветхого Завета и Библии в целом. Автор статьи не является религиозным человеком, однако ему удалось обнаружить некоторые удивительные совпадения (и столь же важные различия) в древнем библейском сюжете и выводах относительно человеческой природы, к которым пришла современная экспериментальная наука. Выявление и анализ подобных закономерностей вдвойне актуальны ещё и потому, что психология является единственной научной дисциплиной, носящей имя богини и исследующей «душу» - по сути, религиозное понятие.

Кратко перескажем значимую для нас часть истории о первородном грехе и его последствиях для человечества. Первые люди, Адам и Ева, беззаботно жили в саду Эдема некоем подобии рая. Однако их счастье кончилось, когда Ева, а затем и Адам отведали плодов с запретного дерева добра и зла. В наказание за это разгневанный бог обрёк первых людей и их потомков на труд, страдания и, в конечном итоге, смерть.

Cиастье, адаптация, позитивные иллюзии. Первоначальная жизнь Адама и Евы в саду Эдема перекликается с человеческой мечтой о счастье. Современная позитивная психология, занимающаяся данной темой, до сих пор не выявила основной «фактор счастья». Похоже, что его и не существует, а беззаботная («райская») жизнь не ведёт к нему определённо.

Более того, на пути к достижению длительного блаженства стоит такой мощный фактор, как адаптация (привыкание, аккомодация). Каждая новая ложка чёрной икры, каждое новое прослушивание любимой песни приносят чуть меньше гедонистического удовольствия, чем предыдущие. Рекламный лозунг «К хорошему привыкают быстро» по сути верен. В лучшем случае, любимая некогда вещь с годами становится просто комфортной в использовании. Конечно, существуют немногие разновидности «позитива», к которым адаптация практически не наступает или идёт очень медленно [4], но они представляют сложные, а потому редко используемые большинством людей виды активности. 
Поэтому (с современных научных позиций) не исключено, что первые люди в саду Эдема постепенно перестали воспринимать «хорошую жизнь» в качестве таковой и согрешили просто от скуки. Как видим, сколько-нибудь длительное счастье недостижимо даже в «райских» условиях, отсекающих любой негатив.

Неким аналогом человеческой мечты о счастье выступают позитивные иллюзии, сравнительно недавно выявленные в нейронаучных и психологических исследованиях у абсолютного большинства испытуемых. Речь идёт о полностью или частично ложных убеждениях положительного свойства [8]. Доказано, что умеренно выраженные позитивные иллюзии (в том числе, надежда на лучшее будущее) помогают человеку легче пережить неприятности в настоящем, дают силы для действий в ситуациях, когда позитивный исход не гарантирован.

Возможность построения «рая на земле» описана в различных утопиях, по сути, представляющих разновидность позитивных иллюзий. История показывает, что все попытки реального воплощения утопий (после революций - например, французской, октябрьской в России, культурной в Китае и т. д.) приводили к ужасным, а отнюдь не «утопическим» последствиям - массовым убийствам и деспотизму правящей власти.

Таким образом, сколько-нибудь длительное «райское наслаждение» для человека в принципе недостижимо. Более того, первоначальное «добро» (лёгкие и быстрые, как правило, телесно ориентированные удовольствия), подвергаясь воздействию адаптации, требует с течением времени всё больших «порций» гедонистической активности индивида ради достижения первоначального «количества» наслаждения. В результате более-менее «разумные» границы потребления отбрасываются. У субъекта формируется аддикция (зависимое поведение), и краткосрочное «добро» переходит в долговременное «зло» [3]. Алкоголизм и переедание являются наиболее яркими примерами зависимого поведения, целью которого теперь становится не получение былого удовольствия, а избегание неудовольствия («ломки»).

Страдания, труд и смысл жсизни. Пришло время поговорить об иных, негативных переживаниях. Как мы помним, на смену «приятной скуке» Адама и Евы в раю пришли страдания и необходимость тяжкого труда.

Прежде всего, отметим определённую эволюционную «ценность» негативных состояний в повседневной («не-райской») жизни. Отрицательно окрашенные переживания полезны тем, что привлекают внимание индивида к событиям, потенциально опасным для его существования. Полное их исчезновение принесло бы серьёзный вред и современному человеку, живущему в сравнительно комфортных и безопасных условиях. Так, лица с врождённым отсутствием чувствительности к боли быстро получают ряд повреждений, по-настоящему опасных для здоровья: множественные переломы костей, серьёзные ожоги, разрывы внутренних органов и т.д.

С другой стороны, как выяснила экспериментальная наука последних десятилетий, над психикой человека действительно довлеет нечто вроде «божественного проклятия». Дело в том, что к негативным событиям и переживаниям индивид более «уязвим», чем к позитивным. Иными словами, «минус» ощущается острее и действует сильнее, чем сопоставимый с ним «плюс».

Например, горечь от расставания с прежним брачным партнёром переживается сильнее и действует дольше, чем радость от знакомства с новым. Отрицательные эмоции при увольнении со старой работы сильнее и длительнее радости от приёма на новую. Для того чтобы устранить у супруга негативное впечатление от одного отрицательного поступка, надо совершить как минимум пять (!) сопоставимых позитивных действий (соотношение Готтмана). Будущие плохие события также произведут более сильное, постоянное, многоуровневое и длительное воздействие на человеческую психику, чем хорошие. Результаты многочисленных исследований подобного рода приведены в обобщающей статье Р. Баумейстера с коллегами [7]. Альберт Эллис, основатель РЭПТ (рацио- 
нально-эмоционально-поведенческой терапии) называл склонность человека к преувеличению негатива «катастрофическим мышлением» [6].

Таким образом, отмечаемая в христианских источниках «большая склонность человека к злу, нежели к добру» [9] имеет определённые научные подтверждения. Речь идёт как о предпочтительном (краткосрочно-гедонистическом) выборе видов добра, впоследствии оборачивающихся долговременным злом, так и большей «проницаемости» психики человека к негативным событиям и переживаниям. Разумеется, с понятием первородного греха (либо с источником грехов) может быть отождествлён и человеческий эгоизм в качестве единственной конечной (первичной, наиболее глубокой) мотивации [2].

В наказание за ослушание Божьей воли люди получили не только страдания, но и труд (Адам и Ева, как известно, вели праздную жизнь в саду Эдема). При этом необходимость трудиться действительно расценивается многими людьми как однозначный негатив. Что ж, никто не спорит, «каторжный» труд не по своей воле представляет собой наказание. Однако у современного человека имеется иная возможность: выбрать занятие «по призванию» и получать радость от его осуществления. Более того, именно тяжёлая (на грани индивидуальных возможностей) активность подобного рода ведёт не только к саморазвитию и самореализации, но также дарит субъекту по-настоящему позитивные (например, потоковые) переживания [5], над которыми не властна адаптация [4].

Захватывающая и напряжённая, приносящая истинное удовлетворение деятельность учёного, продолжающего «вкушать запретные плоды с дерева познания» и при этом мало уязвимого ко многим житейским неприятностям, представляет собой наиболее яркий пример «переворота» ценностей, провозглашённых в Книге Бытия. «Тяжкий» труд становится радостью, адаптация к «хорошему» прекращает своё действие, власть «плохого» отступает. Чем не «рай на земле»- особенно, если сравнивать с жизнью остального человечества?

Остаётся лишь добавить, что современная наука не обнаружила следов какого-либо «высшего» (в том числе, божественного) замысла в отношении человека и Вселенной. Наоборот, «чем лучше учёные познают мир, тем более бессмысленным он им кажется» [1]. В отсутствие релевантных «внешних» источников смысла жизни каждый индивид несёт личную (перед самим собой) ответственность за создание персональной смысловой конструкции - либо за отсутствие таковой и многочисленные негативные последствия. В последнем случае название одной из книг 3. Фрейда «Психопатология обыденной жизни» наилучшим образом отражает суть происходящего.

Bbыводы. Проведённый анализ показывает, что над «массовым» человеком действительно тяготеют негативные закономерности («наказания»), описываемые в Книге Бытия. К их числу относятся: большая проницаемость психики к «плохому», следствием чего являются многочисленные страдания; быстрая адаптация к «хорошему» (гедонистическим удовольствиям); постепенная трансформация кратковременного «хорошего» в долговременное «плохое» (аддикции); отношение к труду как к тягостной необходимости. По контрасту, свободно выбираемая, напряжённая активность творческого и одарённого индивида ведёт к противоположным эффектам: устойчивости к общераспространённым стрессам и неприятностям; практическому отсутствию адаптации к позитивным событиям и переживаниям; «эксклюзивным» (в том числе, потоковым) состояниям; развитию внутреннего потенциала и успешной самореализации.

1. Вайнберг, С. (2004). Мечты об окончательной теории. М.: Едиториал УРСС.

2. Левит, Л. 3. (2017). Универсальный эгоизм. Минск: З. Колас.

3. Левит, Л. 3. (2018). Зло сильнее добра, если добро важнее истины: доказательства и следствия. Психологія особистості, 1 (9), 104-119.

4. Любомирски, С. (2014). Психология счастья. СПб.: Питер.

5. Чиксентмихайи, М. (2011). Поток: психология оптимального переживания. М.: Смысл.

6. Эллис, А. (2002). Гуманистическая психотерапия. М.: ЭКСМО-Пресс.

7. Baumeister, R. F., Bratslavsky, E., Finkenauer, C. \& Vohs, K. D. Bad is stronger than good (2001). Review of General Psychology, 5, 4, 323-370. 
8. Lane, T. J., Flanagan, O. (2013). Neuroexistentialism, eudaimonics, and positive illusions. Mind and Society: Cognitive Science Meets the Philosophy of the Social Sciences. Springer Publishers, 1-28.

9. Первородный грех. Взято из ru.wikipedia.org/wiki/. (Дата обращения 10.07.2019).

\section{REFERENCES}

1. Weinberg, S. (2004). Mechty ob okonchatelnoi teorii [Dreams of a final theory]. Moscow: Editorial URSS. (rus.).

2. Levit, L. Z. (2017). Universalny egoism [Universal egoism]. Minsk: Z. Kolas. (rus.).

3. Levit, L. Z. (2018). Zlo silneje dobra, jesli dobro vazhnee istiny: dokazatelstva i sledstvija [The bad is stronger than the good, if the good is more important than the truth: the proofs and the consequences]. Psihologija osobistosti [Psychology of personality], 1, 104-119. (rus.).

4. Ljubomirski, S. (2014). Psihologija schastja. [Psychology of happiness]. Saint-Petersburg: Piter. (rus.).

5. Csikszentmihalyi, M. (2011). Potok: psihologija optimalnogo perezhivanija. [The flow: the psychology of optimal experience]. Moscow: Smysl. (rus.).

Press. (rus.)

6. Ellis, A. (2002). Gumanisticheskaja psihoterapija [The humanistic psychotherapy]. Moscow: EKSMO-

7. Baumeister, R. F., Bratslavsky, E., Finkenauer, C. \& Vohs, K. D. (2001). Bad is stronger than good [Review of General Psychology], 5, 4, 323-370.

8. Lane, T. J., Flanagan, O. (2013). Neuroexistentialism, eudaimonics, and positive illusions. Mind and Society: Cognitive Science Meets the Philosophy of the Social Sciences. Springer Publishers. 1-28.

9. Pervorodnyi greh [The Original sin]ru.wikipedia.org/wiki/ Retrieved from (Date of access 10.07.2019). (rus.).

\section{Leonid Levit \\ THE BOOK OF BEING AND MODERN PSYCHOLOGY: COINCIDENCE AND DIVERGENCE}

The article regards the coincidence and the divergence between the ancient Biblical myth about the primal sin and some experimental results, obtained by modern science. Thus, the author shows that most people are really subjected to the regularities, which are regarded by religion as the God's punishment for eating the forbidden fruits from the Tree of Knowledge. Mostly, we speak about a higher subjection to the bad than to the good, about a quick adaptation to good, about a transformation of the short-term good into the long-term bad and about attitude to labor as a hard burden. In other words, the greater proneness of a man to the evil than to the good, which is underlined in the Christian sources, has a number of contemporary scientific proofs. Thus, there is created an impression, that a mass person is prone to all the negative regularities, which can be interpreted as the consequence of the divine punishment. In contrast to the above said, creative activity, which is freely chosen by a gifted individual, is governed by the opposite regularities. Namely, it is connected to getting the exclusive positive experience (including the flow) due to high tension, the absence of adaptation to good and, at the same time, a higher stability towards widely spread stresses and negative information in general. It is also characterized by a development of inner potential and successive self-realization. In particular, this is most vividly expressed in creative activity of a scientist, who continues to «eat the forbidden fruits» from the Tree of Knowledge, thus breaking the divine prohibitions and regularities common to most people. In the epoch, when the science cannot discover the external sources of meaning (including the divine plan), every thinking person gets his own responsibility at creating one's own meaningful life construction.

Keywords: adaptation, the good, the evil, positive illusions, religion, meaning. 